INTERNATIONAL HIGHER EDUCATION - NUMBER 68 SUMMER 2012 Pages 20-21.

\title{
South Africa: Challenges of Racism and Access
}

\section{CHIKA SEHOOLE}

Chika Sehoole is professor of education at the University of Pretoria, South Africa. E-mail: chika.sehoole@up.ac.za.

At the end of 2011 and the beginning of 2012, South Africa's higher education sector made national and international news headlines. At the end of 2011, the University of Pretoria was hit by allegations of apparent racism among its staff, where a black engineering professor alleged systematic harassment and victimization, on racial grounds. At the beginning of the 2012 academic year, a black parent was killed in a stampede at the gates of the University of Johannesburg, where crowds of prospective students had gathered in the quest to get admission into this university.

These two incidents-namely, allegations of racism and the quest for access especially of black students in higher education-are just a few examples of the challenges that South Africa experiences in meeting some of the priority areas identified by the postapartheid government, in 1994. In outlining the vision of the postapartheid government, the 2001 National Plan for Higher Education noted the need to increase the number of black members of staff in higher education institutions. This was in line with the changes in the composition of the student body in those institutions. Given the paucity of postgraduate students and, consequently, the small pool of potential recruits, the government encouraged institutions also to recruit black and female staff members from the 
rest of the continent. The alleged victim of racism at the University of Pretoria is a Kenyan national.

\section{RACE AND INSTITUTIONAL CULTURES}

There has been some progress in increasing the number of black students and staff in higher education institutions. The preliminary student headcount in 2011, for the 23 public universities, was 899,120 . This number includes both full-time and part-time enrollments, both for contact and distance-education students. The figure for 1994 was 495,356. Therefore, this represents an increase of almost 82 percent since the advent of democracy. Government redress policies on access

for black and female students have yielded positive results. The number of black (African, colored, and Indian) students increased from 55 percent to 80 percent.

On the other hand, the number of black staff had also increased from 17 percent in 1994 to 44 percent in 2010. Contrary to expectations, however, physical access seems not to be sufficient, although there seems to be improvements. The necessity is to find out what the experiences are of blacks who were excluded and discriminated under the apartheid system. The racial incident in 2008 at the University of Free State, where white students ill-treated black women members of the cleaning staff, and the alleged experience of the black professor at the University of Pretoria are examples that show that written policies are not sufficient to effect the desired changes.

The Soudine Committee investigated the incident at the University of the Free State. The committee's brief covered all the 23 universities. They found that racial discrimination and sexism were both pervasive in many South African universities. In this regard, a change is needed of the institutional cultures. The 
members of the university community will have to embrace a new way of operation and espouse new values of these institutions, in line with democratic dispensation ushered in by the Nelson Mandela administration. Studies have shown that higher education institutions largely ignored the change of institutional cultures. Historically, white institutions, in particular, are unable to recruit or retain black staff members, because their institutional culture is alienating rather than accommodating for new people. This tradition had an impact on black students' success and performance and was also an obstacle toward attracting black students into postgraduate research programs. A strategy to overcome this barrier was to encourage institutions to recruit academics from the rest of the African continent. This could play a significant role for providing role models for black students and helping to change institutional cultures.

\section{AcCess AND the Central ApPlications System}

The unfortunate incident of the death of a parent at the gates of the University of Johannesburg also points to two important policy issues facing South Africa. The first issue relates to the management of primary applicants who want to enter universities, which at the moment is uncoordinated, nationally. The current practice is that students can apply to as many higher education institutions as possible, during their final year of high school. After the release of their grade 12 (matric) results, they are offered places at individual universities where they had applied before. Thus, a student who passed well could be offered a place to study by all the institutions (from two to four) she/he has applied to. However, the student can only take up the place at one institution. 
The second issue relates to the fact that some of the students, who do not apply until they earn their grade 12 results, start looking for an available place to study at the higher education institutions, at the start of the academic year. They literally travel from one institution to another in search of a place to study. Those who did not meet the entrance requirements at their preferred institutions also start looking for alternative places of study at the beginning of the academic year. The combinations of these factors result in long queues of students lining at gates of universities, in search of a place to study. This desperation for access has unfortunately claimed a life at the beginning of 2012 in the University of Johannesburg.

Can there be no better way of managing the process of admission of students into universities? A central applications system has been proposed by government as a solution and a way of combating the recurrence of the incident of the University of Johannesburg. What is interesting to note is that this solution was proposed by the national plan, 11 years ago. The question why this has not been implemented remains a challenge for the government to address.

The stampedes and the long queues at the beginning of every academic year in institutions of higher education also point to another bigger system issue, which is the fact that the South African higher education system is operating at full capacity, and there is a need to build new institutions. Currently, the establishment of two new universities has been approved by the government, and plans are under way to start with the implementation of the policy decision. Until these universities become fully functional, the pressure of the existing institutions will remain. 
There is recognition within the government that the building of additional universities will not meet the demand for access to higher education. In this regard, the government has unveiled a vision of a postschool system, which consists of public and private universities, public and private Further Education and Training colleges, and adult education centers, among others.

It is envisaged that young people will be encouraged to consider alternative forms of postschool opportunities, other than university education. With regard to meeting the needs of individuals who desire to pursue university education, within the limited resources, distance education could be considered as an alternative. 